\title{
Cones and sleeves present good survival and clinical outcome in revision total knee arthroplasty: a meta-analysis
}

\author{
Laura Theresa Fischer $^{1} \cdot$ Markus Heinecke $^{1} \cdot$ Eric Röhner $^{1} \cdot$ Peter Schlattmann $^{2} \cdot$ Georg Matziolis $^{1}$
}

Received: 3 March 2021 / Accepted: 16 July 2021 / Published online: 13 August 2021

(c) The Author(s) 2021

\begin{abstract}
Purpose The fixation of revision total knee arthroplasties (rTKA) tends to be difficult, leading to a reduction in implant survival. One option for achieving a more stable anchorage is to use metaphyseal cones and sleeves. The objective of the present paper is to provide a current comparative meta-analysis on survival and clinical results of cones vs. sleeves, with a differentiation between the short- and long-term outcome.

Methods A search of the literature was conducted systematically to include original papers from 2010 to June 2021. The following parameters were taken into account: revision for aseptic loosening, revision for any reason, periprosthetic joint infections (PJI), KSS as well as KSFS. Studies with a mean follow-up of at least 60 months were defined to be long-term follow-up studies (LT). All other studies were included in the short-term (ST) study analysis. A pooled incidence was used as a summary statistic using a random intercept logistic regression model.

Results The present meta-analysis included 43 publications with 3008 rTKA. Of these, 23 publications with 1911 cases were allocated to the sleeve group (SG) and 20 papers with 1097 cases to the cone group (CG). CG showed overall numerically higher complication rates in short- and long-term follow-up, compared with SG. Aseptic loosening occurred at a rate of $0.4 \%$ in SG (LT) and $4.1 \%$ in CG (LT) $(p=0.09)$. Periprosthetic joint infection (PJI) was more frequent in the cone group (7\% in ST and 11.7\% in LT) than in the sleeve group (3.4\% in ST and 4.9\% in LT, $p=0.02$ both). The total revision rate was $5.5 \%$ in SG (LT) and $14.4 \%$ in CG (LT) $(p=0.12)$. The clinical scores were also comparable between the two groups. Hinged prothesis were used more frequent in the cone group (ST $p<0.001$; LT $p=0.10$ ), whereas CC type protheses were used more frequently in the sleeve group (ST $p<0.001$; LT $p<0.11$ ).

Conclusions This meta-analysis takes into account the longest follow-up periods covered to date. Both cones and sleeves represent a reliable fixation method in the case of severe bone loss in rTKA, although the higher rate of PJI after cone fixation remains a source of concern. A metaphyseal fixation of hinged implants should be taken into account.
\end{abstract}

Level of evidence II (meta-analysis).

Keywords Revision total knee arthroplasty $\cdot$ Total knee replacement $\cdot$ Bone defects $\cdot$ Cones $\cdot$ Sleeves $\cdot$ Aseptic loosening

Laura Theresa Fischer

laurafischer95@googlemail.com

1 Orthopaedic Department Waldkliniken Eisenberg, Orthopaedic Professorship of the University Hospital Jena, Klosterlausnitzer Str. 81, 07607 Eisenberg, Germany

2 Department of Medical Statistics, Informatics and Data Science, Jena University Hospital Jena, Bach Str. 18, 07743 Jena, Germany

\section{Introduction}

Regardless of the reason for revision, implant survival is reduced after revision total knee arthroplasty (rTKA) [23]. One reason for this is the challenging fixation of the implant in the bone stock, which is compromised both in substance and in density $[5,8,14,28,29]$.

Implant fixation and defect management are oriented according to the estimated bone defect and bone quality $[11,28]$. Various techniques are used to achieve the stable anchorage of a revision implant. Apart from cement, allografts, wedges and stem extensions, cones and sleeves have become increasingly popular over the past few years. This 
is because an additional metaphyseal implant anchorage is superior to a sole diaphyseal fixation [22].

Cones may be regarded as metaphyseally anchored metallic bone grafts, which enable a cementless fixation over their porous surface. Sleeves also follow the principle of cementfree metaphyseal anchorage. In contrast to cones, sleeves are firmly attached to the prosthesis. However, it also bears the risk of fractures during broaching, which represents the most common intraoperative complication when sleeves are used [17, 24, 31].

In numerous individual studies, excellent implant survival has been shown both for cones and for sleeves after a medium-term follow-up [6, 9, 12, 17, 21, 23, 33]. The few studies with long-term follow-up ( $>7$ years) $[1,3,6,13,15$, 25] could not be taken into account in previous meta-analyses [18, 27, 30, 34]. Nevertheless, there is initial evidence of a drop in survival over long-term follow-up [1].

It is thereby obvious, that the revision reasons differ depending on timepoint of failure [2,3]. Revisions within the first years after implantation of cones or sleeves may result from failing bony integration or persistence of infection (in septic revisions). In contrast, late revisions may result from aseptic loosening of a primarily integrated implant or new infection. Given a different aetiology of failure, specific information about the short- and long-term outcome of cones and sleeves is missing.

Since all published meta-analyses [18, 27, 30, 34] include studies without differentiation between short- and long-term survival, there is lack of evidence about differing results of cones and sleeves depending on length of follow-up.

The objective of the present paper was therefore to conduct a current comparative meta-analysis on the survival and clinical outcome of cones vs. sleeves. Here, in contrast to previous meta-analyses, short- and long-term (ST vs. LT) follow-up were to be differentiated.

\section{Methods}

\section{Literature search strategy}

The literature search was conducted systematically, following the internationally recognised Preferred Reporting Items for Systematic Reviews and Meta-Analysis (PRISMA) (Fig. 1). The literature databases PubMed, Ovid Medline, GoogleScholar and Cochrane Library were used. The

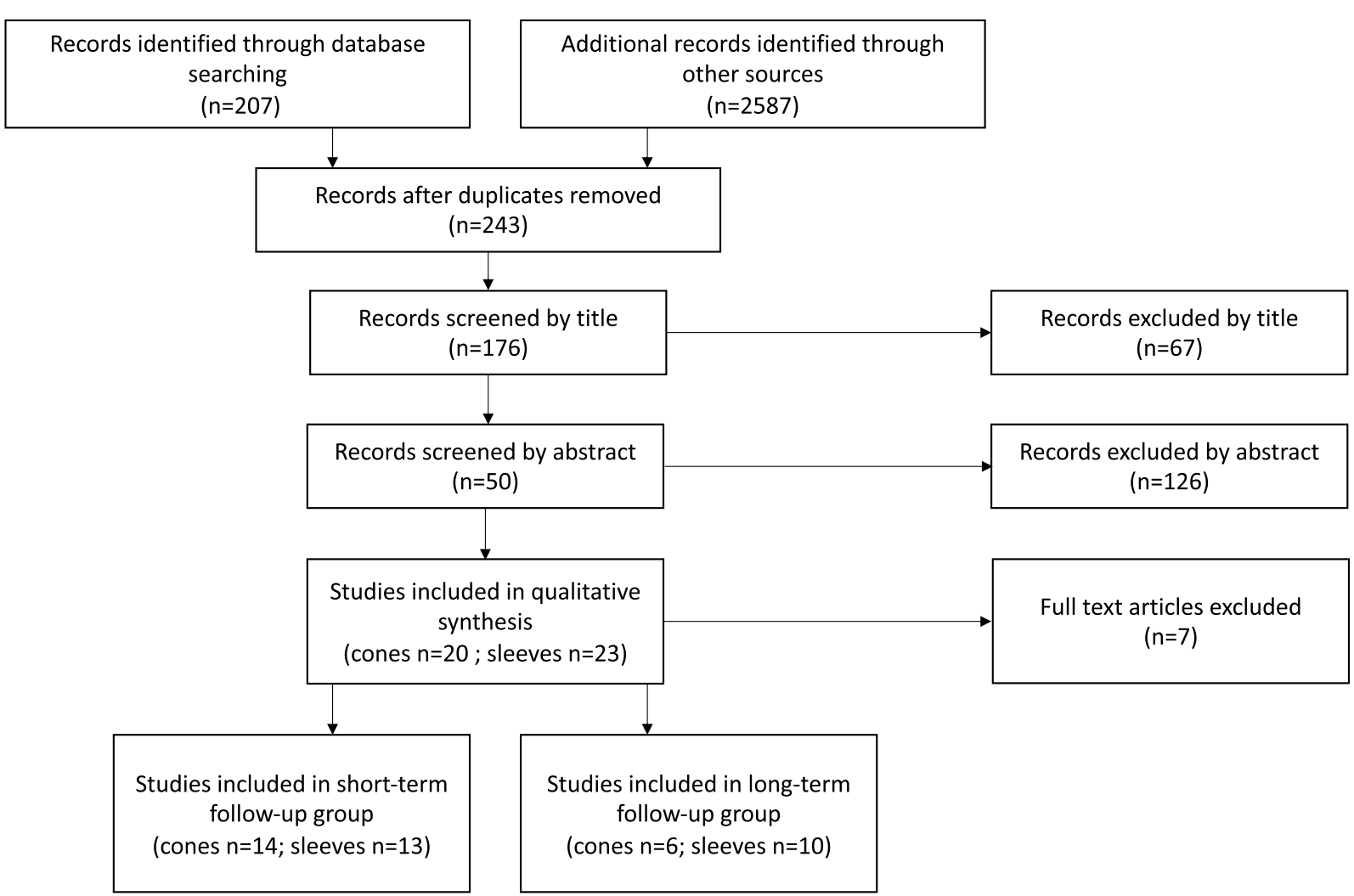

Fig. 1 PRISMA flow diagram of article selection. PRISMA—Preferred Reporting Items for Systematic Reviews and Meta-Analysis 
following search terms were used in combination: ("total knee arthroplasty" OR "revision total knee arthroplasty") AND ("cones" OR "sleeves").

Original papers published in English between 2010 and June 2021 were included after thorough screening of their relevance with regard to content. All publications with a follow-up of less than 1 year were excluded.

The data were extracted both from the text and from the respective tables and figures. For quality assurance, a second reviewer (M.H.) was consulted in the event of uncertainty and a cross-check was carried out.

For the evaluation of survival, the following parameters were selected: number of implant exchanges in total, implant exchanges due to aseptic loosening and septic reoperations with and without implant exchange e.g. DAIR (debridement, antibiotics and implant retention) in periprosthetic joint infections (PJI). Regarding clinical outcome the KSS (Knee Society Score) and KSFS (Knee Society functional Score) were assessed.

Revisions were defined as implant exchange, excluding PE-exchange only. All complications requiring revision but without prosthesis replacement counted as re-operations.

Descriptive data considered were the mean follow-up of the studies, the reasons for revision (index indication), the level of constraint (non-constrained, condylar constrained (CC) or hinged) as well as the patients' age and sex.

\section{Statistics}

Prevalence represents the ratio of the number of patients with complications to the total of number of patients in that study. A pooled prevalence was used as a summary statistic using a random intercept logistic regression model. Accordingly, prevalence was used to enable a forest plot. The horizontal bars in the plots represent the range of confidence interval (CI). A 95\% CI was used in the analysis. Analysis of heterogeneity of prevalence across studies was initially done using a Chi-square test. The degree of heterogeneity was also quantified using $I^{2}$ values. The $I^{2}$ statistic describes the percentage of variation across studies that is due to heterogeneity rather than chance. In this meta-analysis the heterogeneity variance $\operatorname{tau}^{2}$ was estimated based on the maximum likelihood estimate according to a random effects logistic regression model. Publication bias was investigated using Egger's regression test [10]. Statistical analysis was performed using the statistical software $\mathrm{R}$ using the package meta $[4,32]$.

\section{Results}

The present meta-analysis included 43 publications with $n=3008$ rTKA. Of these, 23 publications with 1911 cases were allocated to the sleeve group (SG) and 20 papers with 1097 cases the cone group (CG). In the subgroup analysis according to the respective follow-up period, a total of 27 studies resulted for the ST group and a total of 16 studies were assigned to the LT group. This meta-analysis takes into account the longest follow-up periods covered to date. (Table 1).

SG and CG were comparable with regard to age, sex distribution (male/female) and index indication for revision (septic/aseptic). (Tables 2 and 3).

With regard to the fixation in groups SG and CG, good short- and long-term prosthesis survival times were seen for both devices. No significant difference was found in relation to prosthesis survival (implant exchange for aseptic loosening, implant exchange for any reason) (Figs. 2 and 3). In contrast to that, periprosthetic joint infections (PJI) were twice frequent in the cone group compared to the sleeve group (Table 3, Fig. 4).

For both devices, significant improvements and good results were seen in all scores (KSS, KSFS) postoperatively (Figs. 5 and 6). A significant superiority of one device over the other could not be demonstrated. Hinged prothesis were used at a higher volume in the CG than in the SG whereas $\mathrm{CC}$ type protheses were used more frequently in the SG. (Table 3).

We found publication bias with a bias equal to -2.86 and $p$ value $<0.01$. All papers included were level III (retrospective cohort studies, case-control studies) and IV (case series) studies (Table 4).

\section{Discussion}

The most important finding of the present study was that no difference regarding overall prosthesis survival and clinical outcome could be determined neither in short-term nor in long-term follow-up between fixation using cones compared with sleeves in rTKA. The subgroup analyses for the endpoints "implant exchange for aseptic loosening" and "implant exchange for any reason" showed no statistically significant difference, again regardless of the follow-up period. This result has to be interpreted taking into account, that cones were used more frequently with higher constrained implants than sleeves. The endpoint "PJI" differed significantly between the groups presenting a higher infection rate in the cone group.

Available data are predominantly with short followup. As a result, previous meta-analyses are biased by a 


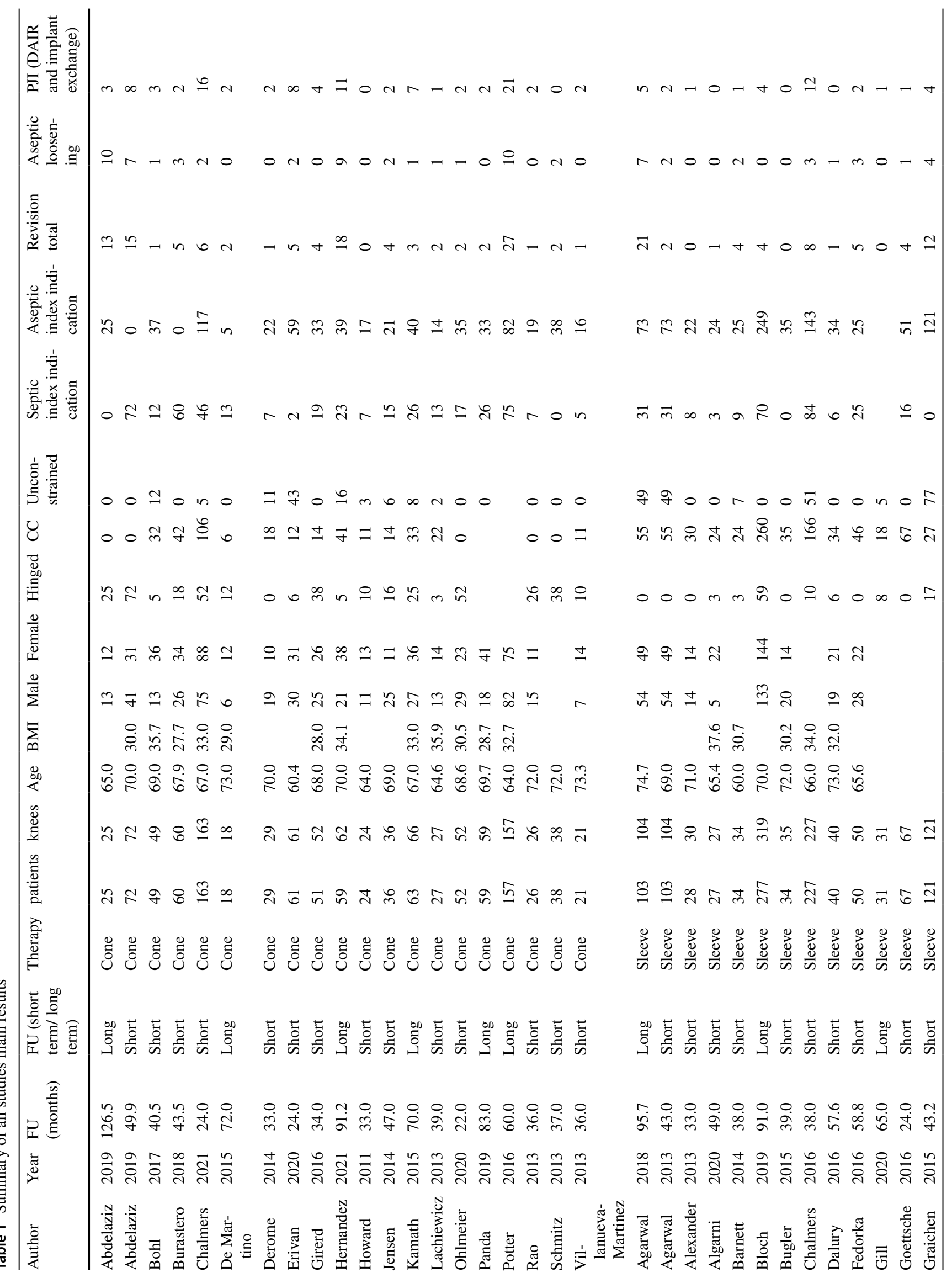




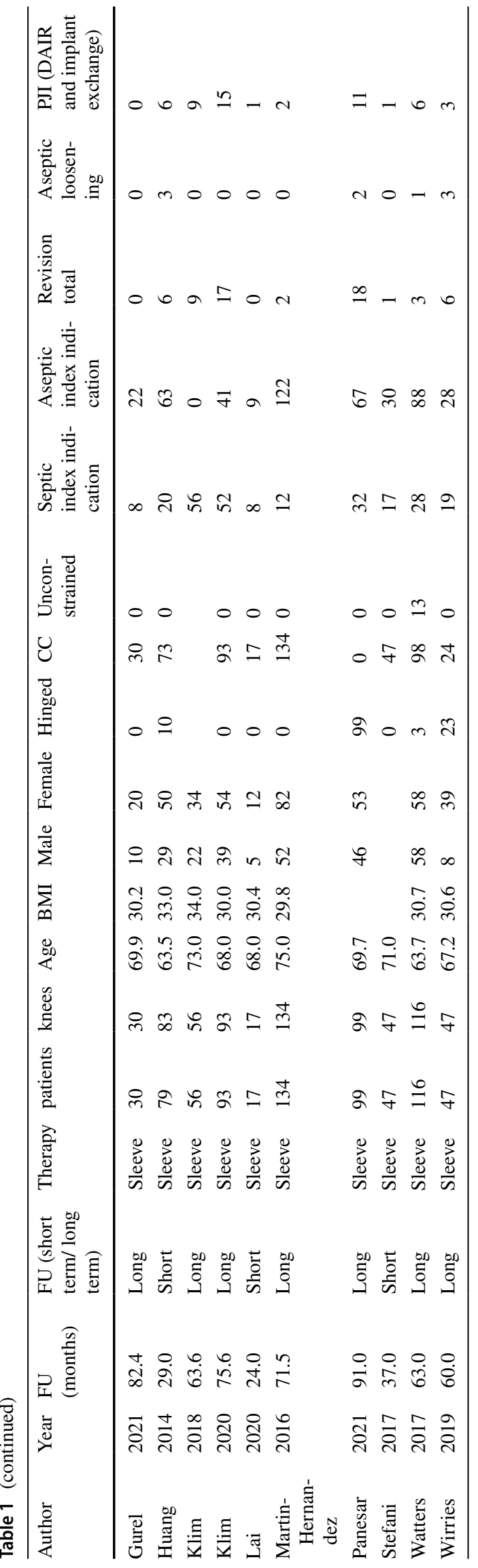

Table 2 Patient's demographics were comparable and without significant differences between the therapy groups

\begin{tabular}{llllll}
\hline Follow-up & Therapy & Age & BMI & Male (\%) & Female (\%) \\
\hline short & cone & 67.8 & 31.5 & 49.0 & 51.0 \\
short & sleeve & 67.1 & 33.2 & 46.0 & 54.0 \\
long & cone & 66.8 & 32.2 & 43.8 & 56.2 \\
long & sleeve & 70.2 & 30.7 & 44.2 & 53.4 \\
\hline
\end{tabular}

disproportionate evaluation of the short-term follow-up and therefore overestimation of reasons for early revisions. These differ between short- and long-term follow-up [2, 3]. Therefore, studies with short- and long-term follow-up were compared separately in the present meta-analysis.

Bone defects and loss of bone substance are frequently encountered in revision total knee arthroplasty and present a challenge to the surgeon, making the implant fixation complicated. However, an optimal implant fixation is essential for a good functional outcome and survival of the prosthesis. Within the context of rTKA implantations, the epiphysis is almost always damaged and cannot be used as the sole fixation zone. In contrast, the metaphysis is usually sufficiently retained and can be used to anchor the implant $[12,22]$. Cones and sleeves are two options available for metaphyseal anchorage.

In knee revision arthroplasty, semi-constrained or hinge prostheses are usually used based on the state of ligaments. Numerous studies have shown that the level of constraint influences the survival time and clinical outcome of the prosthesis. Pure hinge knee prostheses and type 3 bone defects are associated with higher numbers of aseptic loosening and worse clinical outcome $[1,7,26]$. A metaphyseal implant fixation seems to reduce that effect because, despite the significant higher volume of hinged prothesis in the CG, our study shows comparable rates of aseptic loosening between SG and CG. Based on these findings, a metaphyseal fixation of hinged implants should therefore be considered.

Regarding the clinical outcome both devices demonstrated postoperatively significant improvements and good results in all scores (KSS, KSFS) without a significant superiority of one device over the other.

In addition to the aforementioned fixation with cones or sleeves, numerous other factors can influence the subsequent outcome. Levent et al. [20] demonstrated smoking, a large femoral canal anteroposterior diameter and right-sided TKA as significant risk factors for aseptic loosening in TKA. Jasper et al. [16] and Klasan et al. [19] showed younger age, higher knee joint activity and male gender as significant risk factors for repeat revision procedures.

Moreover, both tibial and femoral component can get loose, so that the endpoint loosening is influenced by both components' fixation. Implant geometry, implantation errors 
Table 3 The results illustrating the indication for index revision using cone or sleeve, the degree of implant constraint, the rates of implant exchange for any reason, aseptic loosening, and the rates for operative intervention resulting from PJI

\begin{tabular}{lccc}
\hline short term follow-up $(<5$ years $)$ & Cones & Sleeves & $p$ value \\
\hline Aseptic index RTKA & $61.2(27.8-86.5)$ & $80.8(66.4-90.0)$ & 0.23 \\
Septic index RTKA & $38.9(13.5-72.2)$ & $19.2(10.0-33.6)$ & $1.8(0.4-7.9)$ \\
Hinged implant & $68.2(20.8-94.6)$ & $93.9(77.0-98.6)$ & $<0.001$ \\
CC implant & $20.1(5.5-52.1)$ & $0.3(0.01-9.7)$ & $4.5(2.8-7.1)$ \\
Unconstraint implant & $2.0(0.3-12.2)$ & $2.8(1.8-4.2)$ & 0.37 \\
Implant exchange for any reason & $6.1(3.9-9.3)$ & $3.4(2.1-5.4)$ & 0.35 \\
Implant exchange for aseptic loosening & $4.3(2.8-6.3)$ & Sleeves & 0.16 \\
PJI (with or without implant exchange) & $7.0(4.8-10.0)$ & $60.0(32.7-82.2)$ \\
\hline Long-term follow-up (> 5 years) & Cones & $40.0(17.8-67.3)$ \\
\hline Aseptic index RTKA & $63.9(39.4-82.8)$ & $2.0(0.02-65.1)$ \\
Septic index RTKA & $36.1(17.2-60.6)$ & $89.6(23.7-99.6)$ \\
Hinged implant & $64.0(9.9-96.6)$ & $0.2(0.2-0.2)$ \\
CC implant & $27.7(5.4-72.1)$ & $5.5(2.2-12.7)$ \\
Unconstraint implant & $1.6(0.1-31.8)$ & $0.4(0.1-3.0)$ \\
Implant exchange for any reason & $14.4(5.9-31.0)$ & $4.9(2.6-9.1)$ \\
Implant exchange for aseptic loosening & $4.1(0.8-19.7)$ & 0.83 \\
PJI (with or without implant exchange) & $11.7(8.2-16.3)$ & 0.10 \\
\hline
\end{tabular}

Numbers are given in percent with $95 \%$ confidence interval in brackets and $p$ value for subgroup differences

or compromises (rotation, anterior overstuffing, reduction of posterior offset, mediolateral overhang) are more frequent on the femoral than on the tibial side. Therefore, it is to be expected that the femoral component influences the clinical outcome more than the tibial component.

The higher rate of PJI in the CG compared to the SG remains a source of concern and needs further investigation. This cannot be explained by an inclusion bias because the number of septic index operations did not differ between the groups. Apart from generally known reasons for higher rates of postoperative infections that were not systematically assessed by most studies (e.g. smoking, diabetes, malnutrition, obesity, ASA classification), a possible explanation for higher numbers of PJI can be found in the different material properties of cones and sleeves. Sleeves have a dense surface that is structured by surface finish or coating. In contrast, the structure of cones is formed by interconnecting pores, resulting in a large total surface area. Given a relation between foreign material surface area and the risk of late infection this may explain the trend toward more PJI-related revisions in the cone group.

The meta-analyses already published on the clinical and radiological outcome of cones and sleeves have failed to show any statistically significant superiority of one anchorage method over the other. However, they do show a good clinical and radiological outcome for both devices in shortand medium-term follow-up. [18, 27, 30, 34]
There are some limitations to our study. One is the heterogeneous data pool, as not all the papers included in the meta-analysis stated means and standard deviations. The considerable heterogeneity of the data may additionally result from the fact, that revision operations per se are heterogenous (e.g. indication, bone defect, soft tissue situation, number of previous operations). Another limitation is the number of patients. It is a decimal power smaller than in studies dealing with primary TKA, so that few outliers have a higher impact on the given standard deviations. This meta-analysis is further limited by a significant publication bias that could not be eliminated by additional literature data after a second search. Only in very few cases, the bone defects were classified consistently, which means that an indication bias cannot be ruled out. In addition, the surgical technique, implant anchorage (with regard to cementation and/or additional stem anchorage), level of constraint of the implanted prostheses and the definition of complications, re-operations and revisions are not uniform.

According to present knowledge, cones and sleeves have not been directly checked against each other in a randomised controlled trial yet. All results and conclusions of the present meta-analysis must be considered with respect to the quality of the individual studies. 
Fig. 2 Forest plot illustrating the rates for implant exchange for any reason for cone fixation vs. sleeve fixation with shortterm (A) and long-term followup (B) a

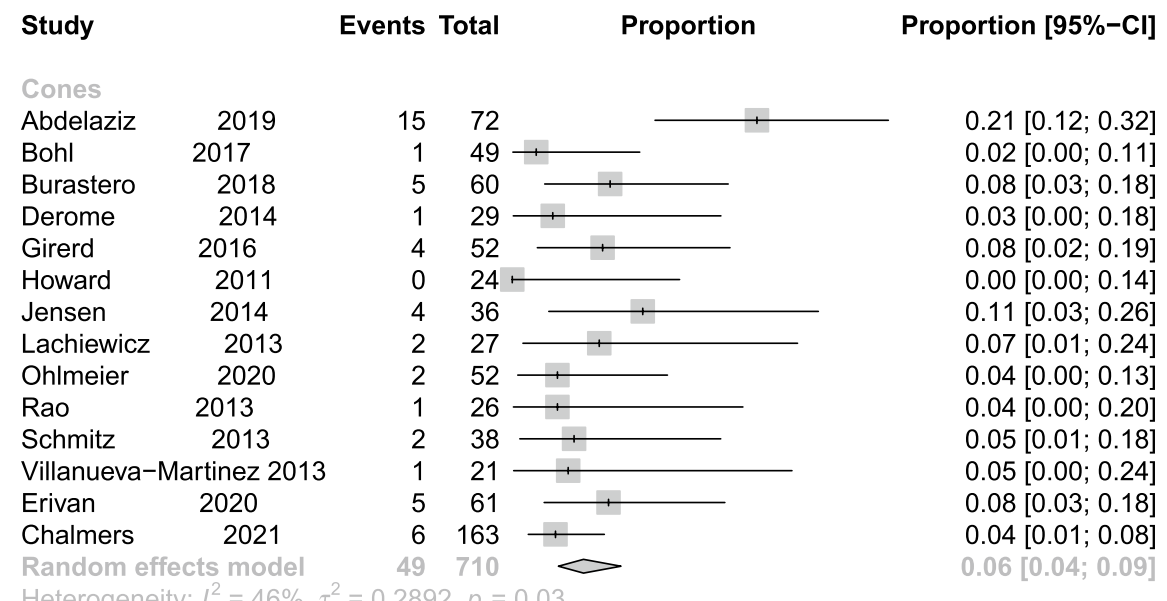

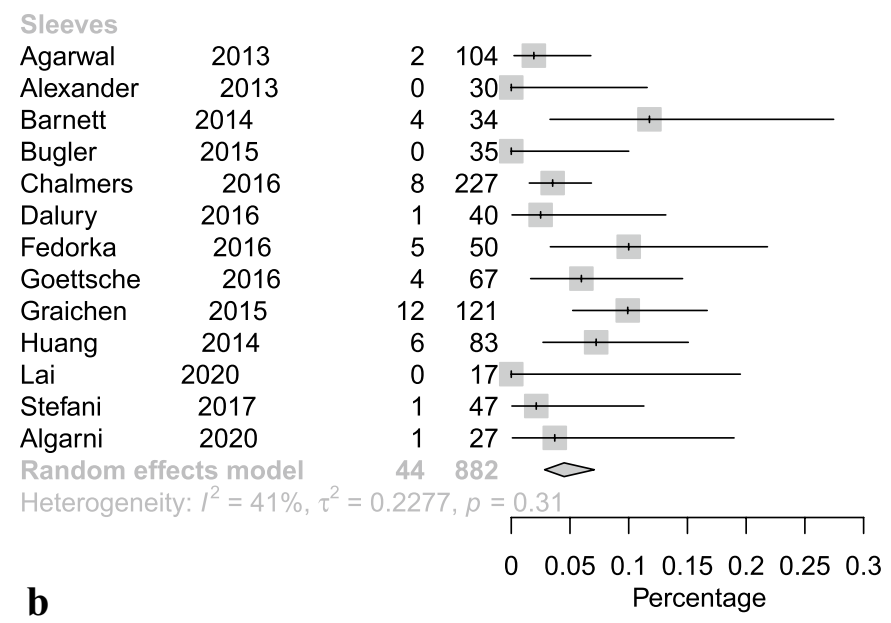

$0.02[0.00 ; 0.07]$ $0.00[0.00 ; 0.12]$ $0.12[0.03 ; 0.27]$ $0.00[0.00 ; 0.10]$ $0.04[0.02 ; 0.07]$ $0.02[0.00 ; 0.13]$ $0.10[0.03 ; 0.22]$ $0.06[0.02 ; 0.15]$ $0.10[0.05 ; 0.17]$ $0.07[0.03 ; 0.15]$ $0.00[0.00 ; 0.20]$ $0.02[0.00 ; 0.11]$ $0.04[0.00 ; 0.19]$ $0.05[0.03 ; 0.07]$

Study

Events Total Proportion

Proportion $[95 \%-\mathrm{Cl}]$

Cones

Abdelaziz

De Martino

2019

Kamath

2015

Panda

2015

Potter 2016

Hernandez

2021

Random effects model

Heterogeneity: $I^{2}=89 \%, \tau^{2}=1.2494, p<0.01$

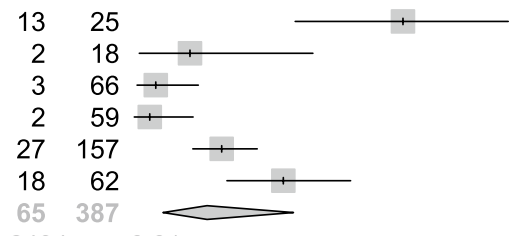

$0.52[0.31 ; 0.72]$

$0.11[0.01 ; 0.35]$

$0.05[0.01 ; 0.13]$

$0.03[0.00 ; 0.12]$

$0.17[0.12 ; 0.24]$

$0.29[0.18 ; 0.42]$

$0.14[0.06 ; 0.31]$

Sleeves

$\begin{array}{lc}\text { Agarwal } & 2018 \\ \text { Bloch } & 2019 \\ \text { Gill } & 2020 \\ \text { Klim } & 2020 \\ \text { Klim } & 2018 \\ \text { Martin-Hernandez } & 2016 \\ \text { Watters } & 2017 \\ \text { Wirries } & 2019 \\ \text { Panesar } & 2021 \\ \text { Gurel } & 2021\end{array}$

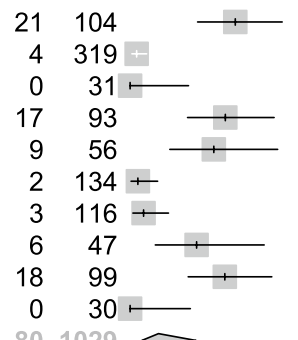

Random effects model

$801029 \prec$

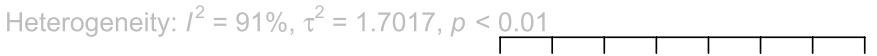

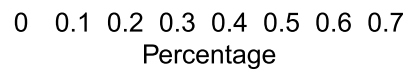

$0.20[0.13 ; 0.29]$

$0.01[0.00 ; 0.03]$

$0.00[0.00 ; 0.11]$

$0.18[0.11 ; 0.28]$

$0.16[0.08 ; 0.28]$

$0.01[0.00 ; 0.05]$

$0.03[0.01 ; 0.07]$

$0.13[0.05 ; 0.26]$

$0.18[0.11 ; 0.27]$

$0.00[0.00 ; 0.12]$

$0.05[0.02 ; 0.13]$ 
Fig. 3 Forest plot illustrating revision rates for aseptic loosening for cone fixation vs. sleeve fixation with short-term (A) and long-term follow-up (B)

a

Study

Events Total

Proportion Proportion [95\%-Cl]

Cones

$\begin{array}{lccc}\text { Lachiewicz } & 2013 & 1 & 27 \\ \text { Bohl } & 2017 & 1 & 49 \\ \text { Howard } & 2011 & 0 & 24 \\ \text { Chalmers } & 2021 & 2 & 163 \\ \text { Erivan } & 2020 & 2 & 61 \\ \text { Abdelaziz } & 2019 & 7 & 72 \\ \text { Jensen } & 2014 & 2 & 36 \\ \text { Ohlmeier } & 2020 & 1 & 52 \\ \text { Rao } & 2013 & 0 & 26 \\ \text { Villanueva-Martinez 2013 } & 0 & 21 \\ \text { Burastero } & 2018 & 3 & 60 \\ \text { Schmitz } & 2013 & 2 & 38 \\ \text { Girerd } & 2016 & 0 & 52 \\ \text { Derome } & 2014 & 0 & 29 \\ \text { Random effects model } & 21 & 710\end{array}$

Random effects model

Heterogeneity: $I^{2}=0 \%, \tau^{2}=0, p=0.50$

$\begin{array}{lc}\text { Sleeves } & \\ \text { Algarni } & 2020 \\ \text { Alexander } & 2013 \\ \text { Goettsche } & 2016 \\ \text { Lai } & 2020 \\ \text { Graichen } & 2015 \\ \text { Agarwal } & 2013 \\ \text { Bugler } & 2015 \\ \text { Fedorka } & 2016 \\ \text { Huang } & 2014 \\ \text { Stefani } & 2017 \\ \text { Chalmers } & 2016 \\ \text { Dalury } & 2016 \\ \text { Barnett } & 2014\end{array}$

Random effects model

Heterogeneity: $I^{2}=0 \%, \tau^{2}$

b

Study

Cones

$\begin{array}{lc}\text { Abdelaziz } & 2019 \\ \text { De Martino } & 2015 \\ \text { Kamath } & 2015 \\ \text { Panda } & 2019 \\ \text { Potter } & 2016 \\ \text { Hernandez } & 2021\end{array}$

Random effects model

Sleeves

$\begin{array}{lc}\text { Agarwal } & 2018 \\ \text { Bloch } & 2019 \\ \text { Gill } & 2020 \\ \text { Klim } & 2020 \\ \text { Klim } & 2018 \\ \text { Martin-Hernandez } & 2016 \\ \text { Watters } & 2017 \\ \text { Wirries } & 2019 \\ \text { Panesar } & 2021\end{array}$

Random effects model

Heterogeneity: $I^{2}=82 \%$

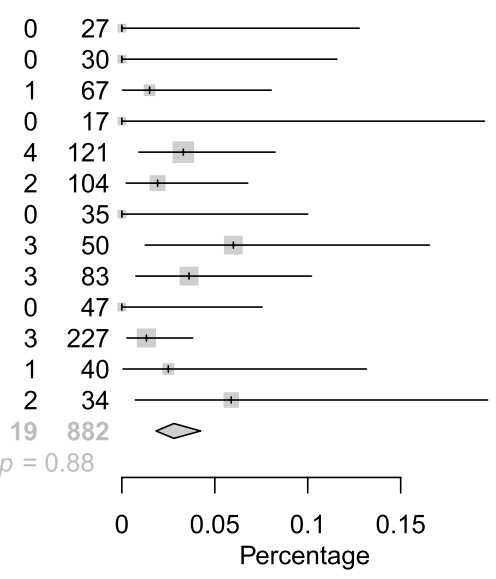

$0.00[0.00 ; 0.13]$ $0.00[0.00 ; 0.12]$ $0.01[0.00 ; 0.08]$ $0.00[0.00 ; 0.20]$ $0.03[0.01 ; 0.08]$ $0.02[0.00 ; 0.07]$ $0.00[0.00 ; 0.10]$ $0.06[0.01 ; 0.17]$ $0.04[0.01 ; 0.10]$ $0.00[0.00 ; 0.08]$ $0.01[0.00 ; 0.04]$ $0.02[0.00 ; 0.13]$ $0.06[0.01 ; 0.20]$ $0.03[0.02 ; 0.04]$

Proportion $[95 \%-\mathrm{Cl}]$

Events Total Proportion

$0.40[0.21 ; 0.61]$

$0.00[0.00 ; 0.19]$

$0.02[0.00 ; 0.08]$

$0.00[0.00 ; 0.06]$

$0.06[0.03 ; 0.11]$

$0.15[0.07 ; 0.26]$

$0.04[0.01 ; 0.20]$

$0.07[0.03 ; 0.13]$

$0.00[0.00 ; 0.01]$

$0.00[0.00 ; 0.11]$

$0.00[0.00 ; 0.04]$

$0.00[0.00 ; 0.06]$

$0.00[0.00 ; 0.03]$

$0.01[0.00 ; 0.05]$

$0.06[0.01 ; 0.18]$

$0.02[0.00 ; 0.07]$

$0.00[0.00 ; 0.12]$

$0.00[0.00 ; 0.03]$ 
Fig. 4 Forest plot illustrating revision for PJI with or without implant exchange for cone fixation vs. sleeve fixation with short-term (A) and long-term follow-up (B) a
Study

Cones

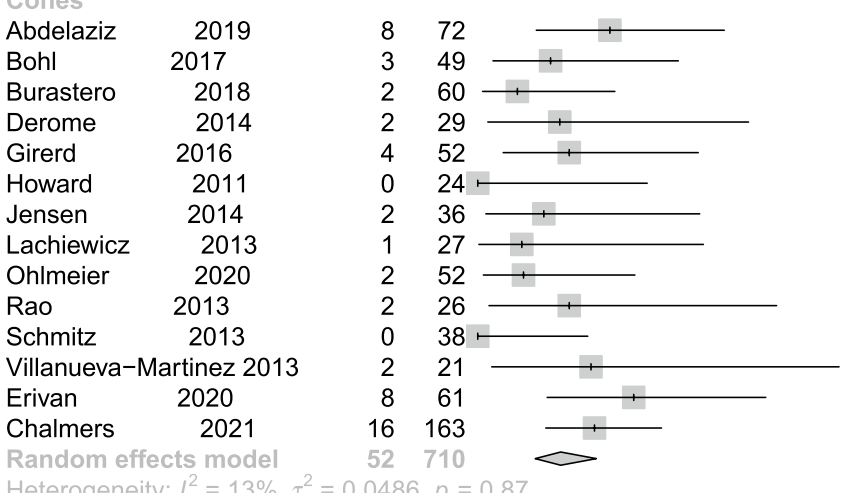

Heterogeneity: $L^{2}=13 \%, \tau^{2}=0.0486, p=0.87$

\section{Events Total}

Proportion

$\begin{array}{lc}\text { Agarwal } & 2013 \\ \text { Alexander } & 2013 \\ \text { Barnett } & 2014 \\ \text { Bugler } & 2015 \\ \text { Chalmers } & 2016 \\ \text { Dalury } & 2016 \\ \text { Fedorka } & 2016 \\ \text { Goettsche } & 2016 \\ \text { Graichen } & 2015 \\ \text { Huang } & 2014 \\ \text { Lai } & 2020 \\ \text { Stefani } & 2017 \\ \text { Algarni } & 2020 \\ \text { Random effects model }\end{array}$

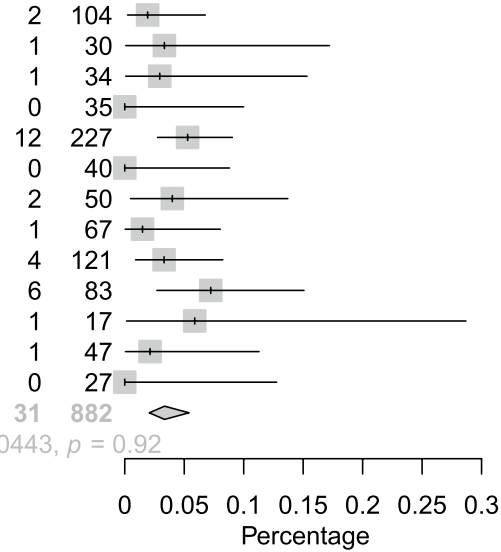

b Percentage
Proportion [95\%-CI]

$0.11[0.05 ; 0.21]$

$0.06[0.01 ; 0.17]$

$0.03[0.00 ; 0.12]$

$0.07[0.01 ; 0.23]$

$0.08[0.02 ; 0.19]$

$0.00[0.00 ; 0.14]$

$0.06[0.01 ; 0.19]$

$0.04[0.00 ; 0.19]$

$0.04[0.00 ; 0.13]$

$0.08[0.01 ; 0.25]$

$0.00[0.00 ; 0.09]$

$0.10[0.01 ; 0.30]$

$0.13[0.06 ; 0.24]$

$0.10[0.06 ; 0.15]$

$0.07[0.05 ; 0.10]$

$0.02[0.00 ; 0.07]$

$0.03[0.00 ; 0.17]$

$0.03[0.00 ; 0.15]$

$0.00[0.00 ; 0.10]$

$0.05[0.03 ; 0.09]$

$0.00[0.00 ; 0.09]$

$0.04[0.00 ; 0.14]$

$0.01[0.00 ; 0.08]$

$0.03[0.01 ; 0.08]$

$0.07[0.03 ; 0.15]$

$0.06[0.00 ; 0.29]$

$0.02[0.00 ; 0.11]$

$0.00[0.00 ; 0.13]$

$0.03[0.02 ; 0.05]$
Study

Cones

$\begin{array}{lc}\text { Abdelaziz } & 2019 \\ \text { De Martino } & 2015 \\ \text { Kamath } & 2015 \\ \text { Panda } & 2019 \\ \text { Potter } & 2016 \\ \text { Hernandez } & 2021\end{array}$

Hernandez 2021

Random effects model

Heterogeneity: $I^{2}=12 \%, \tau^{2}=0.0241, p=0.34$

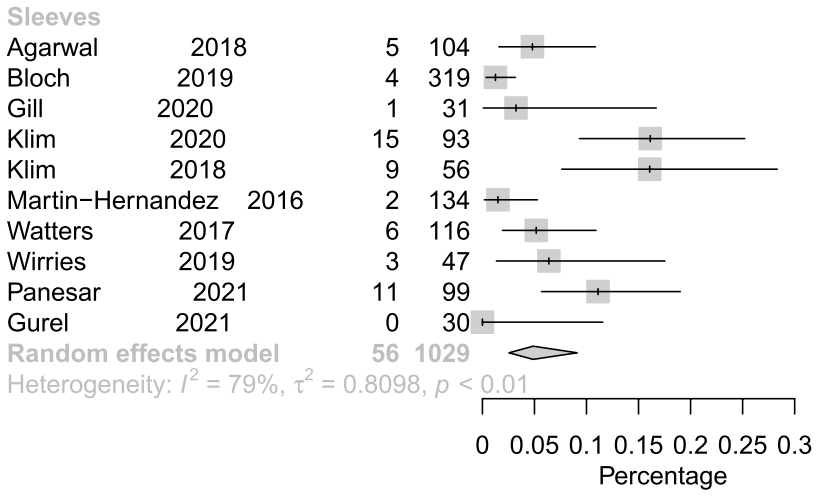

Events Total Proportion

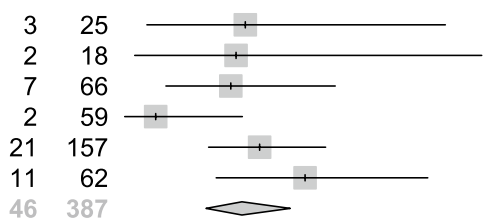

$0.12[0.03 ; 0.31]$

$0.11[0.01 ; 0.35]$

$0.11[0.04 ; 0.21]$

$0.03[0.00 ; 0.12]$

$0.13[0.08 ; 0.20]$

$0.18[0.09 ; 0.30]$

$0.12[0.08 ; 0.16]$
0.05 [0.02; 0.11$]$

$0.01[0.00 ; 0.03]$

$0.03[0.00 ; 0.17]$

$0.16[0.09 ; 0.25]$

$0.16[0.08 ; 0.28]$

$0.01[0.00 ; 0.05]$

$0.05[0.02 ; 0.11]$

$0.06[0.01 ; 0.18]$

$0.11[0.06 ; 0.19]$

$0.00[0.00 ; 0.12]$

$0.05[0.03 ; 0.09]$ 
a

Study

Cones

Lachiewicz

Bohl

Howard

Chalmers

Erivan

Abdelaziz

Jensen

Ohlmeier

Rao

Villanueva-Martinez 2013

Burastero 2018

$\begin{array}{ll}\text { Schmitz } & 2013 \\ \text { Girerd } & 2016\end{array}$

Derome

2014

Random effects mode

SD Total Mean Post-Op

Mean Difference

MD $[95 \%-\mathrm{Cl}]$

$\begin{array}{lllllll}27 & 40.00 & 11.5000 & 27 & 79.00 & 10.1667 & - \\ 49 & 51.40 & 14.7000 & 49 & 79.80 & 15.7000\end{array}$

$\begin{array}{rrrrrrr}49 & 51.40 & 14.7000 & 49 & 79.80 & 15.7000 & \div \\ 24 & 55.00 & 10.0000 & 24 & 81.00 & 6.8333 & -\end{array}$

163.163

61
72

$\begin{array}{lll}36 & 42.00 & 8.1667\end{array}$

52

$\begin{array}{lll}26 & 33.20 & 3.8333\end{array}$

21

$\begin{array}{lll}60 & 44.10 & 7.4000\end{array}$

$\begin{array}{lll}38 & 34.00 & 14.0000\end{array}$

$\begin{array}{lll}52 & 45.00 & 13.0000\end{array}$

$29 \quad 42.0013 .3333$

Heterogeneity: $I^{2}=95 \%, \tau^{2}=69.1207, p<0.01$

$-28.40[-34.42 ;-22.38]$

$-26.00[-30.85 ;-21.15]$

-35.00 [-38.55; -31.45]

-47.90 [-49.46; -46.34]

-41.30 [-43.65; -38.95]

-29.00 [-35.26; -22.74]

$-40.00[-46.57 ;-33.43]$

$-35.36[-41.04 ;-29.69]$

\begin{tabular}{|c|c|c|c|c|}
\hline \multicolumn{5}{|l|}{ Sleeves } \\
\hline Algarni & 2020 & 27 & 102.90 & $35.60 c$ \\
\hline Alexander & 2013 & 30 & 55.50 & \\
\hline Goettsche & 2016 & 67 & 62.70 & \\
\hline Lai & 2020 & 17 & 41.00 & \\
\hline Graichen & 2015 & 121 & 88.00 & \\
\hline Agarwal & 2013 & 104 & & \\
\hline Bugler & 2015 & 35 & & \\
\hline Fedorka & 2016 & 50 & & \\
\hline Huang & 2014 & 83 & & \\
\hline Stefani & 2017 & 47 & 39.00 & \\
\hline Chalmers & 2016 & 227 & & \\
\hline Dalury & 2016 & 40 & 36.00 & \\
\hline Barnett & 2014 & 34 & 41.70 & \\
\hline $\begin{array}{l}\text { Random e } \\
\text { Heterogen }\end{array}$ & $\begin{array}{l}\text { cts model } \\
\text { y: not appli }\end{array}$ & 882 & & \\
\hline
\end{tabular}

b Study Total Mean $\begin{array}{r}\text { Pre-Op } \\ \text { SD }\end{array}$

Cones

Abdelaziz

Panda

Hernandez

Potter

Kamath

De Martino

\section{5}

SD Total Mean SD

$$
\begin{array}{rr}
30 & 92.00 \\
67 & 109.60 \\
17 & 71.00 \\
121 & 147.00 \\
104 & . \\
35 & 81.30 \\
50 & . \\
83 & . \\
47 & 77.00 \\
227 & . \\
40 & 90.00 \\
34 & 88.70 \\
882 &
\end{array}
$$

$\begin{array}{lll}27 & 130.20 & 33.7000\end{array}$

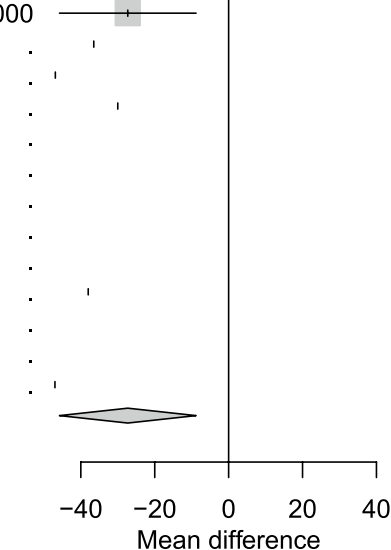

-27.30 [-45.79; -8.81$]$
-36.50
-46.90
-30.00
-59.00

$-38.00$

$-54.00$

$-47.00$

$-27.30[-45.79 ;-8.81]$

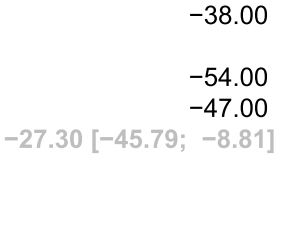

MD [95\%-Cl]

-34.20 [-37.72; -30.68]

$-18.00[-21.28 ;-14.72]$

-25.00 [-29.73; -20.27]

-46.00 [-52.38; -39.62]

$-30.60[-41.46 ;-19.74]$

$-1.00$

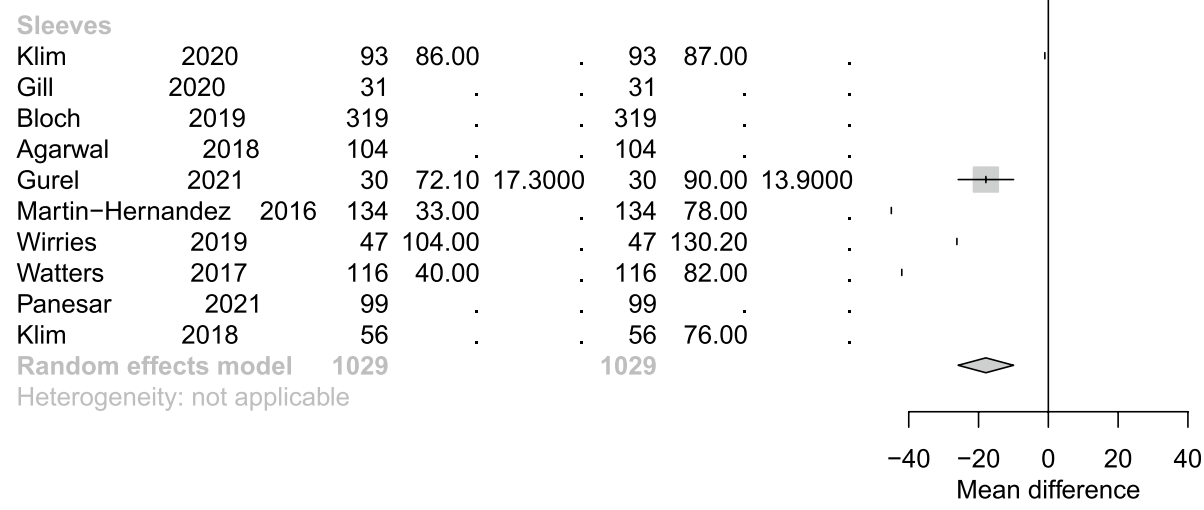

$-17.90[-25.84 ;-9.96]$

$-45.00$

$-26.20$

$-42.00$

$-17.90[-25.84 ;-9.96]$

Fig. 5 Forest plot illustrating clinical outcome with KSS values in sleeve vs. cone fixation with short-term (A) and long-term follow-up (B) 


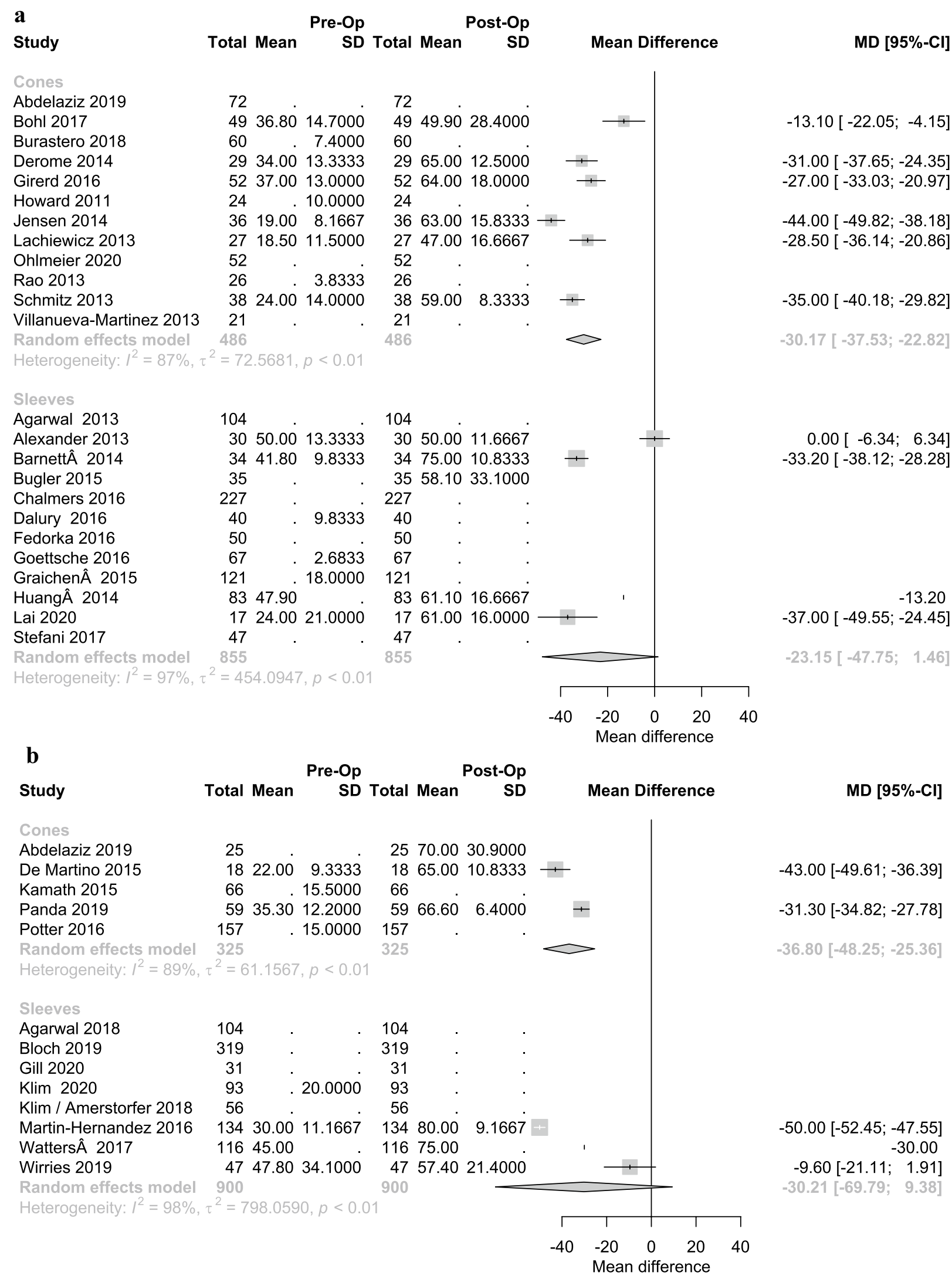

Fig. 6 Forest plot illustrating clinical outcome with KSFS values in sleeve vs. cone fixation with short-term (A) and long-term follow-up (B) 


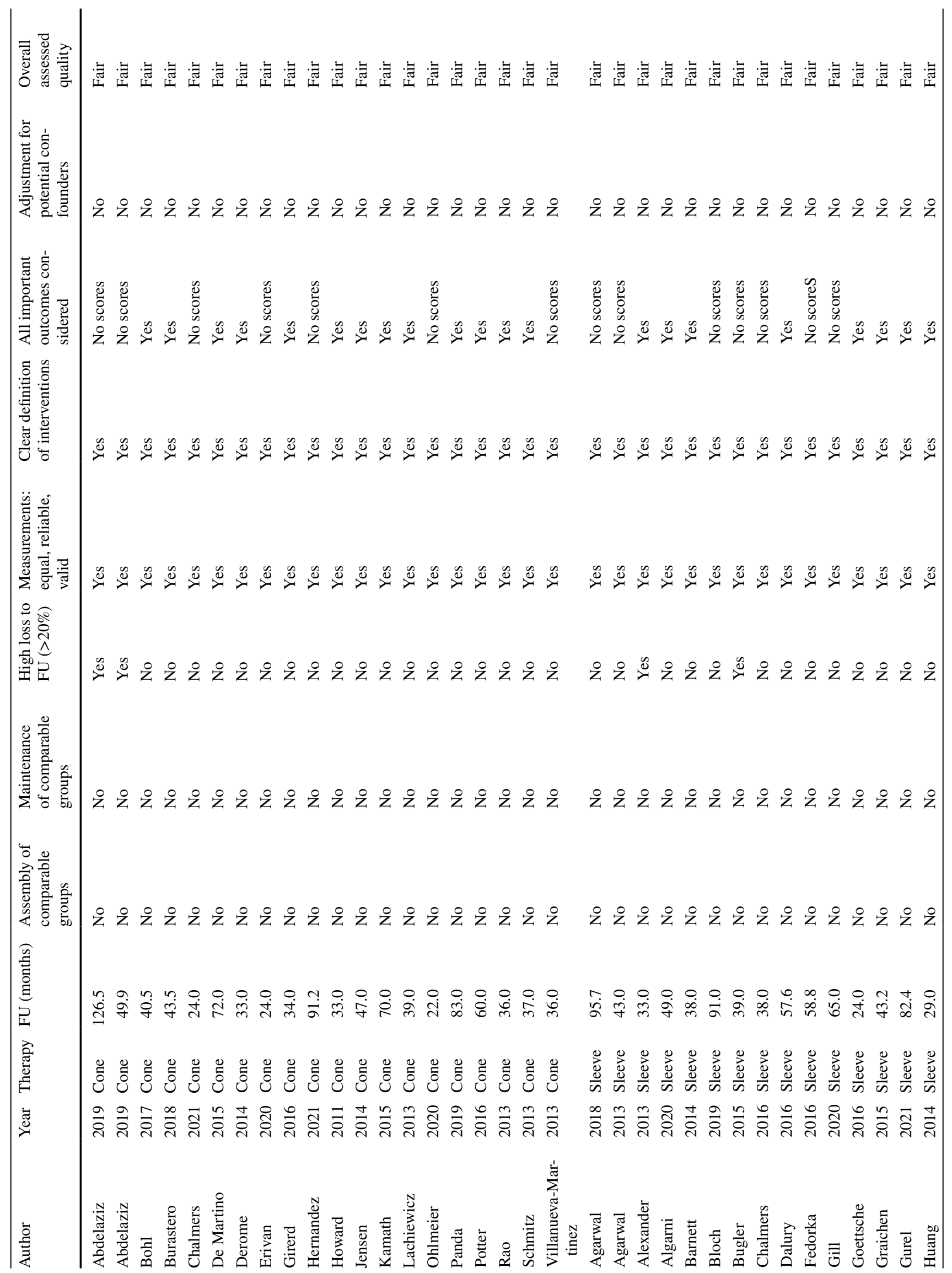




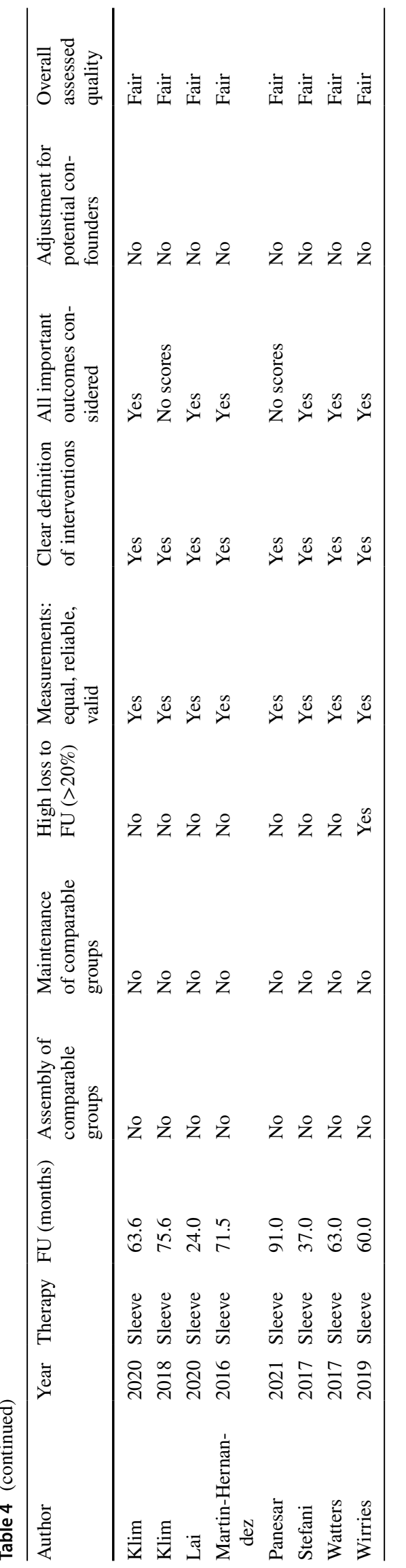

\section{Conclusion}

In conclusion, both cones and sleeves represent a reliable fixation method for revision knee arthroplasty in the case of severe bone loss. Based on our results, we recommend taking an additional metaphyseal fixation of hinged implants into account. While there is no apparent superiority of one method over the other regarding the overall survival and clinical outcome, the higher rate of PJI after cone fixation remains a source of concern.

Funding Open Access funding enabled and organized by Projekt DEAL. No funding or grants were obtained for this study.

\section{Declarations}

Conflict of interest The authors declare that they have no conflict of interest.

Ethical approval Resulting from the study design (meta-analysis) an ethical approval is not applicable. All included studies declared compliance to ethical standards. Table 1 contains a summary of all includes studies. We ourself, did not do any work with human participants and laboratory animals to establish this meta-analysis.

Open Access This article is licensed under a Creative Commons Attribution 4.0 International License, which permits use, sharing, adaptation, distribution and reproduction in any medium or format, as long as you give appropriate credit to the original author(s) and the source, provide a link to the Creative Commons licence, and indicate if changes were made. The images or other third party material in this article are included in the article's Creative Commons licence, unless indicated otherwise in a credit line to the material. If material is not included in the article's Creative Commons licence and your intended use is not permitted by statutory regulation or exceeds the permitted use, you will need to obtain permission directly from the copyright holder. To view a copy of this licence, visit http://creativecommons.org/licenses/by/4.0/.

\section{References}

1. Abdelaziz H, Jaramillo R, Gehrke T, Ohlmeier M, Citak M (2019) Clinical survivorship of aseptic revision total knee arthroplasty using hinged knees and tantalum cones at minimum 10-year follow-up. J Arthroplasty 34:3018-3022

2. Agarwal S, Azam A, Morgan-Jones R (2013) Metal metaphyseal sleeves in revision total knee replacement. Bone Joint $\mathrm{J}$ 95:1640-1644

3. Agarwal S, Neogi DS, Morgan-Jones R (2018) Metaphyseal sleeves in revision total knee arthroplasty: minimum seven-year follow-up study. Knee 25:1299-1307

4. Balduzzi S, Rücker G, Schwarzer G (2019) How to perform a meta-analysis with R: a practical tutorial. Evid Based Ment Health 22:153-160

5. Bernatz JT, Brooks AE, Squire MW, Illgen RI II, Binkley NC, Anderson PA (2019) Osteoporosis is common and undertreated prior to total joint arthroplasty. J Arthroplasty 34:1347-1353 
6. Bloch BV, Shannak OA, Palan J, Phillips JR, James PJ (2020) Metaphyseal sleeves in revision total knee arthroplasty provide reliable fixation and excellent medium to long-term implant survivorship. J Arthroplasty 35:495-499

7. Burastero G, Cavagnaro L, Chiarlone F, Alessio-Mazzola M, Carrega G, Felli L (2018) The use of tantalum metaphyseal cones for the management of severe bone defects in septic knee revision. J Arthroplasty 33:3739-3745

8. Chang CB, Kim TK, Kang YG, Seong SC, Kang S-B (2014) Prevalence of osteoporosis in female patients with advanced knee osteoarthritis undergoing total knee arthroplasty. J Kor Med Sci 29:1425-1431

9. De Martino I, De Santis V, Sculco PK, D’Apolito R, Assini JB, Gasparini G (2015) Tantalum cones provide durable mid-term fixation in revision TKA. Clin Orthop Relat Res 473:3176-3182

10. Egger M, Smith GD, Schneider M, Minder C (1997) Bias in metaanalysis detected by a simple, graphical test. BMJ 315:629-634

11. Engh GA (2006) Classification of bone defects femur and tibia. Springer, Knee arthroplasty handbook, pp 116-132

12. Gill UN, Ahmed N, Noor SS, Memon IA, Memon ZA (2020) Management of the bone loss by metaphyseal sleeves in primary and revision knee arthroplasty: clinical experience and outcome after forty three cases. Int Orthop. https://doi.org/10.1007/ s00264-020-04663-1

13. Gurel R, Morgan S, Elbaz E, Ashlenazi I, Snir N, Kadar A et al (2021) Mid-term clinical and radiographic outcomes of porouscoated metaphyseal sleeves used in revision total knee arthroplasty. Knee Surg Rel Res 33:1-6

14 Ha CW, Park YB (2020) Underestimation and undertreatment of osteoporosis in patients awaiting primary total knee arthroplasty. Archiv Orthop Trauma Surg. https://doi.org/10.1007/ s00402-020-03462-y

15 Hernandez NM, Hinton ZW, Wu CJ, Ryan SP, Bolognesi MP (2021) Mid-term results of tibial cones : reasonable survivorship but increased failure in those with significant bone loss and prior infection. Bone Joint J 103-B:158-164

16. Jasper L, Jones C, Mollins J, Pohar S, Beaupre L (2016) Risk factors for revision of total knee arthroplasty: a scoping review. BMC Musc Disord 17:1-9

17. Kamath AF, Lewallen DG, Hanssen AD (2015) Porous tantalum metaphyseal cones for severe tibial bone loss in revision knee arthroplasty: a five to nine-year follow-up. JBJS 97:216-223

18. Kim HJ, Lee O-S, Lee SH, Lee YS (2018) Comparative analysis between cone and sleeve in managing severe bone defect during revision total knee arthroplasty: a systematic review and metaanalysis. J Knee Surg 31:677-685

19. Klasan A, Magill P, Frampton C, Zhu M, Young SW (2021) Factors predicting repeat revision and outcome after aseptic revision total knee arthroplasty: results from the New Zealand Joint Registry. Knee Surg Sports Traumatol Arthrosc 29:579-585

20. Levent A, Suero EM, Gehrke T, Bakhtiari IG, Citak M (2021) Risk factors for aseptic loosening in complex revision total knee arthroplasty using rotating hinge implants. Int Orthop 45:125-132

21. Martin-Hernandez C, Floria-Arnal LJ, Muniesa-Herrero MP, Espallargas-Donate T, Blanco-Llorca JA, Guillen-Soriano M et al
(2017) Mid-term results for metaphyseal sleeves in revision knee surgery. Knee Surg Sports Traumatol Arthrosc 25:3779-3785

22. Morgan-Jones R, Oussedik S, Graichen H, Haddad F (2015) Zonal fixation in revision total knee arthroplasty. Bone Joint J 97:147-149

23. Panda I, Wakde O, Singh H, Rajgopal A (2018) Management of large bone defects around the knee using porous tantalum trabecular metal cones during complex primary and revision total knee arthroplasty. Paper presented at: Seminars in Arthroplasty 2018

24. Panegrossi G, Ceretti M, Papalia M, Casella F, Favetti F, Falez F (2014) Bone loss management in total knee revision surgery. Int Orthop 38:419-427

25. Panesar K, Al-Mouazzen L, Nessa L, Jonas SC, Agarwal S, Morgan-Jones R (2021) Revision total knee arthroplasty using an uncemented metaphyseal sleeve, rotating hinge prosthesis: a case series of 99 patients. J Arthroplasty 36:2121-2125

26. Potter GD III, Abdel MP, Lewallen DG, Hanssen AD (2016) Midterm results of porous tantalum femoral cones in revision total knee arthroplasty. JBJS 98:1286-1291

27 Roach RP, Clair AJ, Behery OA, Thakkar SC, Iorio R, Deshmukh AJ (2020) Aseptic loosening of porous metaphyseal sleeves and tantalum cones in revision total knee arthroplasty: a systematic review. J Knee Surg. https://doi.org/10.1055/s-0040-1701434

28. Rosso F, Cottino U, Dettoni F, Bruzzone M, Bonasia DE, Rossi R (2019) Revision total knee arthroplasty (TKA): mid-term outcomes and bone loss/quality evaluation and treatment. J Orthop Surg Res 14:280

29. Russell LA (2013) Osteoporosis and orthopedic surgery: effect of bone health on total joint arthroplasty outcome. Curr Rheumatol Reports 15:371

30. Scott KL, Abdel MP, Hanssen AD (2018) Metaphyseal sleeves and cones in revision total knee arthroplasty. In: Bono JV, Scott RD, (eds) Revision total knee arthroplasty. Springer International Publishing, Cham, pp 131-141. https://doi.org/10.1007/978-3319-67344-8_10

31 Sculco PK, Abdel MP, Hanssen AD, Lewallen DG (2016) The management of bone loss in revision total knee arthroplasty: rebuild, reinforce, and augment. Bone Joint J 98-B:120-124

32. Team RC (2013) R: a language and environment for statistical computing

33. Watters TS, Martin JR, Levy DL, Yang CC, Kim RH, Dennis DA (2017) Porous-coated metaphyseal sleeves for severe femoral and tibial bone loss in revision TKA. J Arthroplasty 32:3468-3473

34 Zanirato A, Formica M, Cavagnaro L, Divano S, Burastero G, Felli L (2019) Metaphyseal cones and sleeves in revision total knee arthroplasty: two sides of the same coin? Complications, clinical and radiological results-a systematic review of the literature. Musculoskelet Surg. https://doi.org/10.1007/s12306-019-00598-y

Publisher's Note Springer Nature remains neutral with regard to jurisdictional claims in published maps and institutional affiliations. 